\title{
Toward the Total Synthesis of Ryanodol via Oxidative Alkyne-1,3- Diketone Annulation: Construction of a Ryanoid Tetracycle
}

\author{
Kang Du, ${ }^{\dagger, \S ®}$ Matthew J. Kier, ${ }^{\dagger, \S}$ Arnold L. Rheingold, ${ }^{\ddagger}$ and Glenn C. Micalizio*,† \\ ${ }^{\dagger}$ Department of Chemistry, Dartmouth College, Burke Laboratory, Hanover, New Hampshire 03755, United States \\ ${ }^{*}$ Department of Chemistry, University of California-San Diego, La Jolla, California 92093, United States
}

\section{Supporting Information}

ABSTRACT: A synthetic strategy conceived with the intent of establishing a novel approach to the de novo construction of ryanoids is described that is based on a recently developed metallacycle-mediated intramolecular oxidative alkyne-1,3diketone coupling reaction. In short, a one-pot annulation/ oxidation sequence is shown to be capable of establishing a densely oxygenated polycyclic intermediate that could be converted to a composition of matter that contains the $\mathrm{ABCD}$
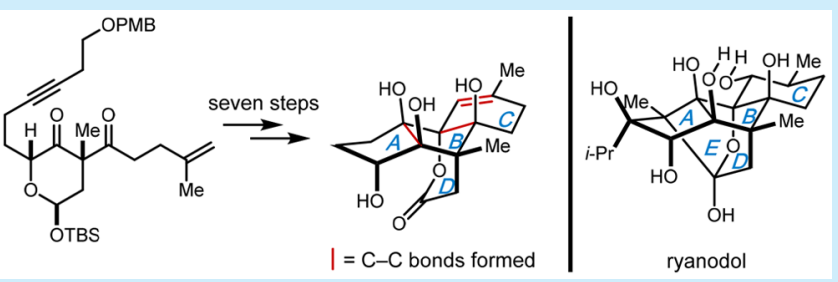
tetracyclic ring system present in the ryanoid family of natural products.

$\mathrm{R}$ yanodol (Figure 1A) has a rich history in organic chemistry and biology. This natural diterpene from the South American plant Ryana speciosa Vahl was originally identified as the hydrolysis product of ryanodine, a compound that alters the function of an intracellular calcium channel known as the ryanodine receptor, and a natural product that has been used as a tool to understand the role that intracellular $\mathrm{Ca}^{2+}$ channels play in biology. ${ }^{1}$ Over the past two decades, structure-activity relationships associated with ryanodine, ryanodol, and synthetic esters of ryanodol/ryanodine have led to the conclusion that a wide variety of ryanoids have diverse and potent effects on $\mathrm{Ca}^{2+}$ channels in vivo, despite the wide range of binding affinities reported for them. ${ }^{\text {la }}$ From a chemical standpoint, ryanodine and ryanodol first stood as complex problems for structure elucidation due, in part, to the great number of fully substituted carbon atoms in their complex polycyclic skeletons. After years of investigation, ${ }^{2}$ Wiesner reported the structure of ryanodine in 1967,3 arrived at by a study that was later described by Pierre Deslongchamps as "one of the most brilliant accomplishments in structure elucidation using chemical degradation." ${ }^{4 a}$ Soon after Wiesner's report, an X-ray crystal structure of the $p$-bromobenzoate of ryanodol was reported that supported Wiesner's proposal and clarified the stereochemistry at $\mathrm{C} 3$. $^{4 \mathrm{~b}}$

The intricate structure of ryanodol has presented a significant challenge for chemical synthesis. It has a caged pentacyclic skeleton that includes 11 stereogenic centers, all of which are contiguous. More daunting is the fact that eight contiguous stereocenters have fully substituted carbon atoms (including two quaternary centers). There have only been three reported total syntheses of ryanodol, the first appearing from Deslongchamps nearly 40 years ago ${ }^{5}$ and two additional recent reports from Inoue ${ }^{6}$ and Reisman. ${ }^{7}$ In all cases, these triumphs in organic chemistry featured unique strategies to address the challenging carbocyclic structure of the natural product: (1) Deslongchamps' early success hinged on strategic use of Diels-Alder chemistry, Baeyer-Villiger oxidation, and an interesting oxidative cleavage/transannular aldol cascadenotably, these efforts nurtured the group's great interest in understanding the role that stereoelectronic effects play in organic chemistry, ${ }^{8}(2)$ Inoue's creative design employed a $C_{2}$ symmetric fused tricycle, radical allylation, Pd-catalyzed olefin isomerization, and ring-closing metathesis, while (3) Reisman's stunningly step-economical strategy featured an interesting $\mathrm{Rh}$ catalyzed Pauson-Khand reaction and a $\mathrm{SeO}_{2}$-mediated polyoxidation process.

Our interest in ryanodol, and ryanoids more broadly, is driven by our desire to explore fundamentally novel approaches to the assembly of densely oxygenated carbocyclic systems. Paying close attention to the central five-membered ring of the ryanoids (ring B; Figure 1A), we have embraced this highly subsituted domain as pressure for both the development of a new carbocycle-forming annulation reaction, as well as the central structural element that will guide our strategy to the incredibly complex carbocyclic structures of the natural product family. As illustrated in Figure 1B, we have recently developed an oxidative annulation reaction that proceeds by intramolecular addition of an alkyne to a 1,3diketone, the quenching of which with $t-\mathrm{BuOOH}$ results in complex polyoxygenated carbocyclic systems $(\mathbf{1} \rightarrow \mathbf{2}) .^{9}$ The means by which we imagined use of this reaction in an approach to the synthesis of ryanoids is depicted in Figure 1C. With an intermediate lactone akin to $\mathbf{I}$ in hand, the oxidative annulation reaction was anticipated to be capable of delivering product II, and hydrolysis of this intermediate was reasoned capable of delivering the bicyclic carboxylic acid III that could serve as an intermediate en route to the tricyclic product IV

Received: August 29, 2018

Published: September 28, 2018 
A. Ryanodol, anhydroryanodol, and the stripped-down polycylic skeleton.
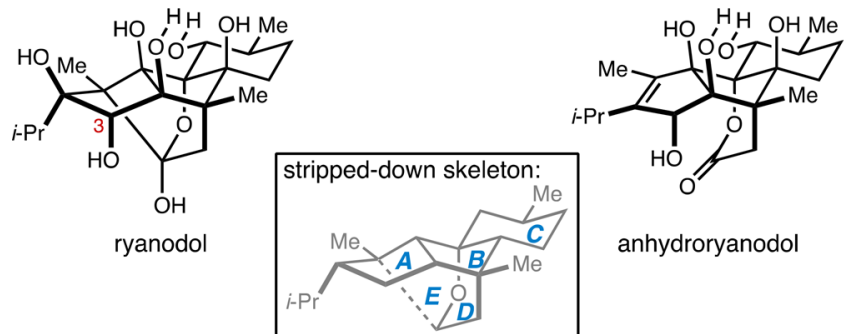

anhydroryanodol

B. An intramolecular oxidative annulation reaction between alkynes and 1,3-diketones.

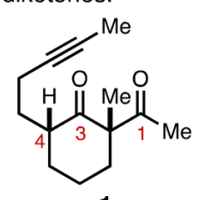

1

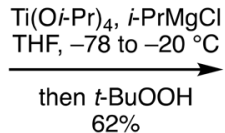

$62 \%$

Synthetic strategy for de novo synthesis of ryanoids based on an oxidative annulation reaction and subsequent regioselective epoxide opening
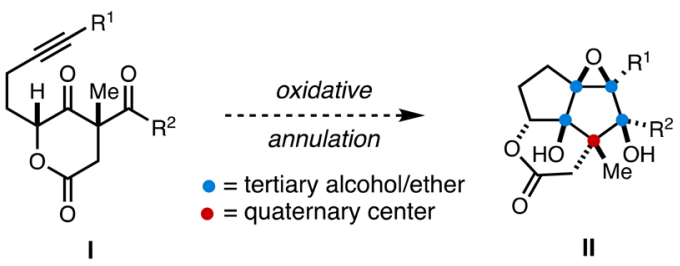

II 'hydrolysis

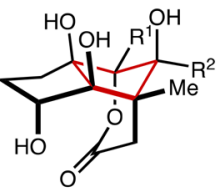

IV
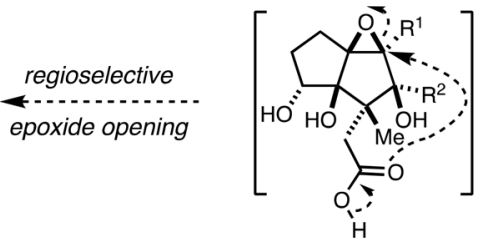

III
Figure 1. Introduction.

through regioselective opening of the fully substituted epoxide. Here, we describe our initial studies aimed at realizing such a sequence of chemical transformations.

As illustrated in Figure 2, the unsaturated aldehyde $3{ }^{10}$ was converted to the lactol 4 by initial reaction with 2 -lithio-furan, and subsequent oxidation and cyclization (NBS, $\mathrm{NaHCO}_{3}$ $\mathrm{NaOAc}$, THF $\left./ \mathrm{H}_{2} \mathrm{O}\right) .{ }^{11}$ Oxidation to the lactone $\left(\mathrm{CrO}_{3}\right.$, $\left.\mathrm{H}_{2} \mathrm{SO}_{4}\right)^{12}$ followed by reduction of the enone $(\mathrm{Zn}, \mathrm{AcOH})$ furnished the intermediate 5 in $59 \%$ overall yield. With this species in hand, it was anticipated that site-selective deprotonation of the ketone could be accomplished with LDA, and that subsequent acylation with an unsaturated activated ester or acid chloride (6) would deliver the 1,3diketone product 7 . Unfortunately, while seemingly straightforward, all efforts to accomplish this transformation were met with failure.

Hypothesizing that the lactone carbonyl may be the structural feature that thwarted these initial attempts, we moved forward with an approach that would allow for the desired formation of a 1,3-diketone in the absence of this structural motif. As illustrated, lactol 4 was selectively protected as its corresponding TBS-ether (TBSOTf, 2,6lutidine), and subsequent conjugate reduction with $\mathrm{CuI} / \mathrm{LAH}$ delivered a 2:1 mixture of isomeric products favoring isomer 9. ${ }^{13}$ After purification, ketone 9 was advanced to a suitable aunnulation substrate $(\mathbf{1 2})$ by initial acylation of an intermediate lithium enolate with the acyl cyanide 10, and subsequent diastereoselective methylation (KHMDS, MeI, THF).

With the stereodefined alkynyl 1,3-diketone in hand, efforts were then directed toward achieving the desired oxidative annulation reaction. As depicted in Figure 3A, initial exploration pursued these two transformations in sequence. Exposure of 12 to the combination of $\mathrm{Ti}(\mathrm{O} i-\mathrm{Pr})_{4}$ and $i$ $\mathrm{PrMgCl}$ in THF $\left(-78\right.$ to $\left.-20^{\circ} \mathrm{C}\right)$, followed by an aqueous quench, led to formation of the highly oxygenated and stereodefined product 13 in 56\% yield. Notably, no evidence was found for the production of a stereoisomeric product in this transformation. Polyol 13 was then advanced to the stereodefined epoxide 14 with high selectivity in $66 \%$ yield by treatment with $\mathrm{VO}(\mathrm{acac})_{2}$ and $t$ - $\mathrm{BuOOH} .{ }^{14}$

Alternatively, a one-pot oxidative annulation was investigated for the direct conversion of $\mathbf{1 2}$ to 14. Exposure of $\mathbf{1 2}$ to $\mathrm{Ti}(\mathrm{O} i-\mathrm{Pr})_{4}$ and $i$-PrMgCl, followed by quenching with $t$ $\mathrm{BuOOH}$, delivered the highly oxygenated and stereodefined product 14 in $43 \%$ yield. An empirical model for this oxidative annulation reaction is illustrated in Figure $3 \mathrm{~B}$ and features

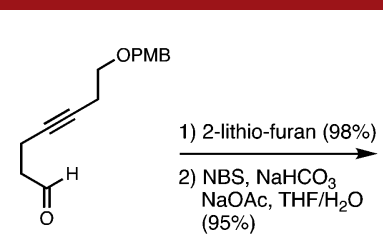

3

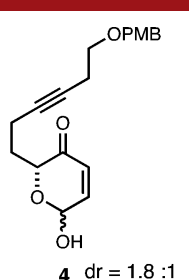

$4 \mathrm{dr}=1.8$

1) TBSOTf, lutidine, $\mathrm{CH}_{2} \mathrm{Cl}_{2}(93 \%)$

2) Cul, LAH, THF/HMPA ( $86 \%$ )

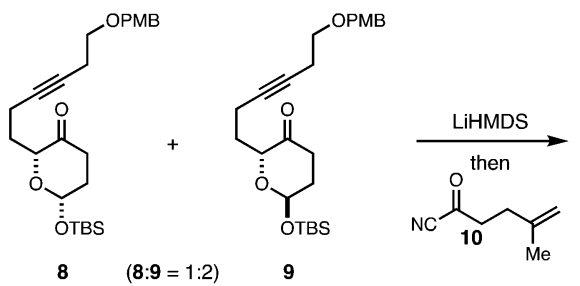

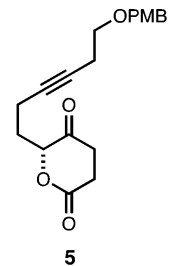
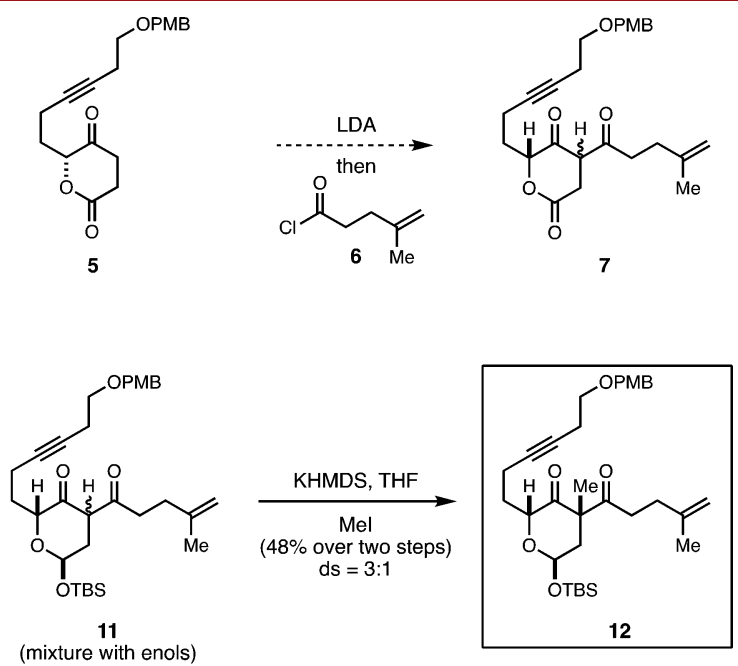

Figure 2. Assembly of a substrate for study of the oxidative annulation. 
A. The metallacycle-mediated alkyne-diketone annulation:

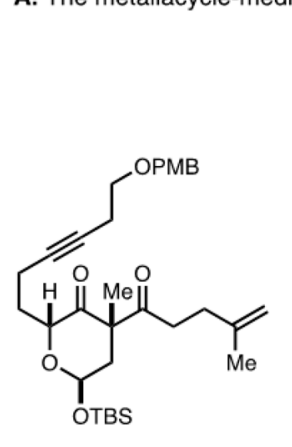

12

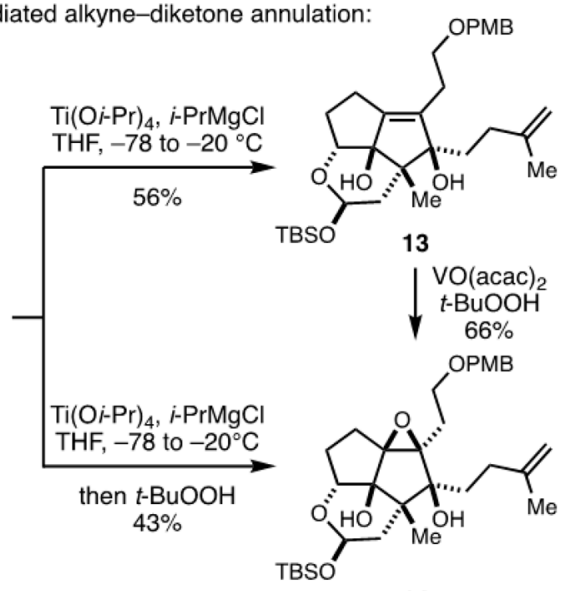

14

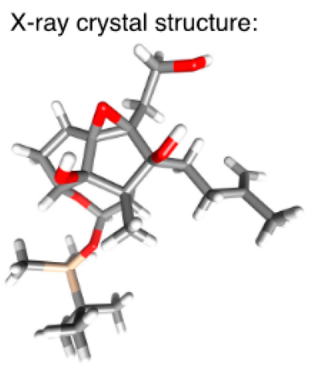

$=$

B. Empirical model for the oxidative annulation of 12 en route to 14 :

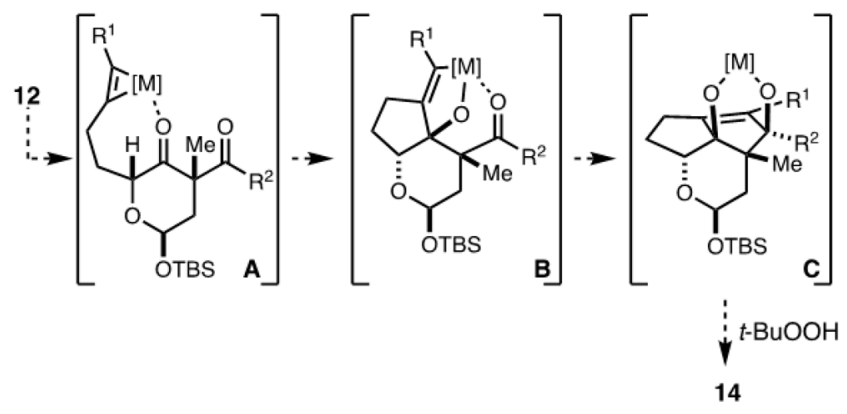

Figure 3. Metallacycle-mediated diketone-alkyne annulation. proposed initial formation of a metallacyclopropene (A) followed by stereoselective intramolecular addition to the proximal ketone to generate an oxametallacyclopentene intermediate (B). Driven by the loss of a $\sigma_{\mathrm{Ti}-\mathrm{C}}$ bond and formation of a $\sigma_{\mathrm{Ti}-\mathrm{O}}$ bond, this intermediate is thought to participate in a second stereoselective intramolecular $\mathrm{C}-\mathrm{C}$ bond-forming event to deliver a carbocyclic product containing a dioxametallacyclohexane (C). Finally, by embracing the inherent reactivity of metal alkoxides in hydroxyl-directed epoxidation chemistry, simply adding $t-\mathrm{BuOOH}$ results in directed oxidation and production of the fully functionalized product 14 as a single stereoisomer. The structure of 14 was confirmed by removal of the PMB ether with DDQ to deliver the polyol 15 which produced a suitable crystal for X-ray diffraction (Figure 3A).

Next, Grieco elimination, ${ }^{15}$ followed by desilylation (TBAF, THF) and oxidation of the hemiacetal with TPAP, $\mathrm{NMO}^{16}$ delivered the lactone intermediate $\mathbf{1 6}$ in $83 \%$ yield over three steps (Figure 4A). A two-step process consisting of treatment with $\mathrm{NaOH}$ in $\mathrm{DME} / \mathrm{H}_{2} \mathrm{O}$, followed by ring-closing metathesis with the Hoveyda-Grubbs second generation catalyst, ${ }^{17}$ then delivered a 1:3 mixture of the tetracyclic products $\mathbf{1 7}$ and $\mathbf{1 8}$ in $71 \%$ overall yield. ${ }^{6}$ This molecular transformation presumably begins by lactone hydrolysis followed by regioselective epoxide opening in a stereoelectronically favored 6-exo manner. While both electrophilic sites of the epoxide may participate in a 6exo ring opening process, ${ }^{18}$ two factors may play a significant role in controlling the regioselectivity for this reaction: (1) nucleophilic addition at C12 would result in a highly strained trans-fused bicyclo[3.3.0] octane motif, ${ }^{19}$ and (2) the C11 position is activated by the neighboring alkene. ${ }^{20}$ While those not familiar with previous studies to prepare ryanadol may be disappointed by the observation that both 17 and 18 are produced in this two-step process, the propensity for the bridging lactone to participate in translactonization chemistry between the $\mathrm{C} 11$ and $\mathrm{C} 3$ hydroxy groups is well understood. ${ }^{5}$ That said, isomers $\mathbf{1 7}$ and $\mathbf{1 8}$ proved to be inseparable in our hands, defining a reality that thwarted our early attempts at characterization of the products of this two-step process.

To secure our understanding of the structures of $\mathbf{1 7}$ and 18, a molecular transformation was sought that would convert this

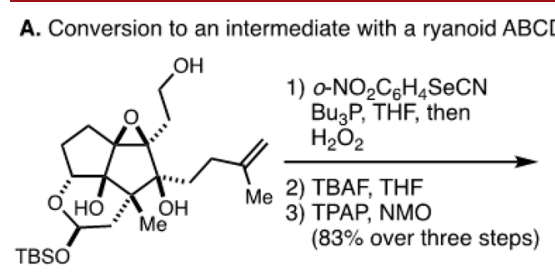

15

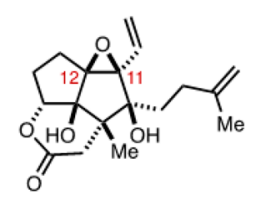

16 i) $\mathrm{NaOH}, \mathrm{DME}, \mathrm{H}_{2} \mathrm{O}$ ii) Hoveyda-Grubbs (II)

PhMe, $70{ }^{\circ} \mathrm{C}$ (71\% over 2 steps)

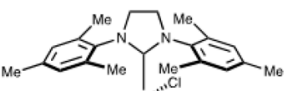

Hoveyda-Grubbs (II)

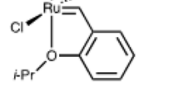

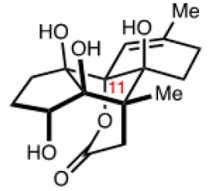

17

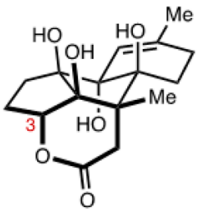

$(\mathbf{1 7}: 18=1: 3)$
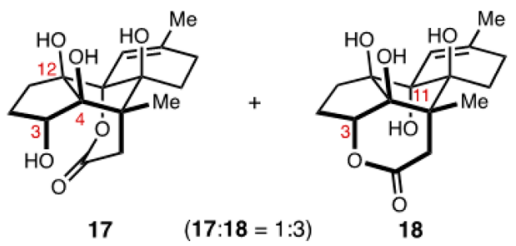

Dess-Martin $\stackrel{\text { periodinane }}{\longrightarrow}$

$99 \%$
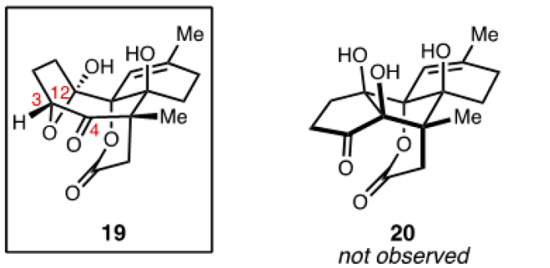

X-ray crystal structure:

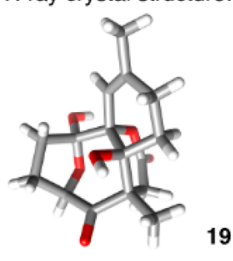

Figure 4. Advancing a product of oxidative diketone-alkyne annulation to a tetracyclic ABCD system of anhydroryanodol. 
product mixture to a single molecular entity suitable for characterization. While reduction of the lactones to the corresponding primary alcohol was viewed as a simple means to accompolish this, we opted to avoid such a transformation, as the polyol product was anticipated to have an undesirable solubility profile. Alternatively, we directed our attention to oxidation chemistry as a means to achieve our goal. As illustrated in Figure 4B, we were delighted to discover that exposing the 3:1 mixture of lactone isomers to the Dess-Martin periodinane resulted in an exceptionally efficient transformation. While it was hoped that it may be possible to selectively oxidize the $\mathrm{C} 3$ alcohol of $\mathbf{1 7}$ to the corresponding ketone, and establish an equilibrium such that 18 would be first converted to 17 and then oxidized to 20, this oxidation procedure instead furnished the bridged polycyclic product 19 in $99 \%$ yield. This product presumably derives from oxidative cleavage of the $\mathrm{C} 4-\mathrm{C} 12$ syn diol, followed by hemiketal formation between the $\mathrm{C} 3$ secondary alcohol and the resulting $\mathrm{C} 12$ ketone. The exceptional efficiency of this transformation indicates that isomerization of the lactone (from the $\mathrm{C} 3$ secondary alcohol to the C11 tertiary alcohol) must be occurring under the reaction conditions.

Overall, we report a new approach to the assembly of the carbocyclic skeleton of ryanoids by application of a recently developed oxidative alkyne-1,3-diketone annulation reaction. The emerging strategy demonstrates that a functionalized heterocyclic diketone is a suitable substrate for this oxidative annulation reaction, and that additional $\pi$-unsaturation is tolerated (i.e., a 1,1-disubstituted alkene) in the organometallic transformation. Further, these investigations also highlight the value of a polyoxygenated intermediate like 14 as an intermediate in the synthesis of the ryanoid skeleton, as siteselective intramolecular epoxide opening preferentially occurs at $\mathrm{C} 11$ rather than C12. Remaining challenges in this developing approach to the ryanoids include the additional substitution required in ring A (at $\mathrm{C} 1$ and $\mathrm{C} 2$ ), as well as selective hydration of the C-ring alkene. Studies to address these challenges are underway.

\section{ASSOCIATED CONTENT}

\section{Supporting Information}

The Supporting Information is available free of charge on the ACS Publications website at DOI: 10.1021/acs.orglett.8b02767.

Procedures and spectroscopic data (PDF)

\section{Accession Codes}

CCDC 1864763 and 1867194 contain the supplementary crystallographic data for this paper. These data can be obtained free of charge via www.ccdc.cam.ac.uk/data_request/cif, or by emailing data_request@ccdc.cam.ac.uk, or by contacting The Cambridge Crystallographic Data Centre, 12 Union Road, Cambridge CB2 1EZ, UK; fax: +44 1223336033.

\section{AUTHOR INFORMATION}

\section{Corresponding Author}

*E-mail: glenn.c.micalizio@dartmouth.edu. ORCID $\odot$

Kang Du: 0000-0001-6778-4733

Glenn C. Micalizio: 0000-0002-3408-5570

\section{Author Contributions}

${ }^{\S}$ K.D. and M.J.K. contributed equally. Notes

The authors declare no competing financial interest.

\section{ACKNOWLEDGMENTS}

The authors acknowledge financial support from the National Institutes of Health (GM124004).

\section{REFERENCES}

(1) (a) Bidasee, K. R.; Besch, H. R. J. J. Biol. Chem. 1998, 273, 12176-12186. (b) McPherson, P. S.; Campbell, K. P. J. Biol. Chem. 1993, 268, 13765-13768. (c) Meissner, G. Annu. Rev. Physiol. 1994, 56, 485-508. (d) Fill, M.; Copello, J. A. Physiol. Rev. 2002, 82, 893922. (e) McCauley, M. D.; Wehrens, X. H. T. Acta Pharmacol. Sin. 2011, 32, 749-757. (f) Jenden, D. J.; Fairhurst, A. S. Pharmacol. Rev. 1969, 21, 1-25.

(2) Wiesner, K. Pure Appl. Chem. 1963, 7, 285-296.

(3) Wiesner, K.; Valenta, Z.; Findlay, J. A. Tetrahedron Lett. 1967, 8, $221-225$.

(4) (a) Deslongchamps, P.; Bélanger, A.; Berney, D. J. F.; Borschberg, H.-J.; Brousseau, R.; Doutheau, A.; Durand, R.; Katayama, H.; Lapalme, R.; Leturc, D. M.; Liao, C.-C.; MacLachlan, F. N.; Maffrand, J.-P.; Marazza, F.; Martino, R.; Moreau, C.; Ruest, L.; Saint-Laurent, L.; Saintonge, R.; Soucy, P. Can. J. Chem. 1990, 68, 115-126. (b) Srivastava, S. N.; Przybylska, M. Can. J. Chem. 1968, 46, 795-797.

(5) (a) Bélanger, A.; Berney, D. J. F.; Borschberg, H. J.; Brousseau, R.; Doutheau, A.; Durand, R.; Katayama, H.; Lapalme, R.; Leturc, D. M.; Liao, C.-C.; Maclachlan, F. N.; Maffrand, J. P.; Marazza, F.; Martino, R.; Moreau, C.; Saintlaurent, L.; Saintonge, R.; Soucy, P.; Ruest, L.; Deslongchamps, P. Can. J. Chem. 1979, 57, 3348-3354. (b) Deslongchamps, P.; Bélanger, A.; Berney, D. J. F.; Borschberg, H. J.; Brousseau, R.; Doutheau, A.; Durand, R.; Katayama, H.; Lapalme, R.; Leturc, D. M.; Liao, C.-C.; Maclachlan, F. N.; Maffrand, J. P.; Marazza, F.; Martino, R.; Moreau, C.; Ruest, L.; Saintlaurent, L.; Saintonge, R.; Soucy, P. Can. J. Chem. 1990, 68, 127-152. (c) Deslongchamps, P.; Bélanger, A.; Berney, D. J. F.; Borschberg, H. J.; Brousseau, R.; Doutheau, A.; Durand, R.; Katayama, H.; Lapalme, R.; Leturc, D. M.; Liao, C.-C.; Maclachlan, F. N.; Maffrand, J. P.; Marazza, F.; Martino, R.; Moreau, C.; Ruest, L.; Saintlaurent, L.; Saintonge, R.; Soucy, P. Can. J. Chem. 1990, 68, 186-192. (d) Deslongchamps, P.; Bélanger, A.; Berney, D. J. F.; Borschberg, H. J.; Brousseau, R.; Doutheau, A.; Durand, R.; Katayama, H.; Lapalme, R.; Leturc, D. M.; Liao, C.-C.; Maclachlan, F. N.; Maffrand, J. P.; Marazza, F.; Martino, R.; Moreau, C.; Ruest, L.; Saintlaurent, L.; Saintonge, R.; Soucy, P. Can. J. Chem. 1990, 68, 115-126. (e) Deslongchamps, P.; Bélanger, A.; Berney, D. J. F.; Borschberg, H. J.; Brousseau, R.; Doutheau, A.; Durand, R.; Katayama, H.; Lapalme, R.; Leturc, D. M.; Liao, C.-C.; Maclachlan, F. N.; Maffrand, J. P.; Marazza, F.; Martino, R.; Moreau, C.; Ruest, L.; Saintlaurent, L.; Saintonge, R.; Soucy, P. Can. J. Chem. 1990, 68, 153-185.

(6) (a) Nagatomo, M.; Koshimizu, M.; Masuda, K.; Tabuchi, T.; Urabe, D.; Inoue, M. J. Am. Chem. Soc. 2014, 136, 5916-5919. (b) Masuda, K.; Koshimizu, M.; Nagatomo, M.; Inoue, M. Chem. Eur. J. 2016, 22, 230-236.

(7) Chuang, K. V.; Xu, C.; Reisman, S. E. Science 2016, 353, 912915.

(8) Deslongchamps, P. Stereoelectronic Effects in Organic Chemistry; Baldwin, J. E., Ed.; Pergamon Press, Inc.: 1983, Oxford, U.K.; p 375.

(9) Kier, M. J.; Leon, R. M.; O’Rourke, N. F.; Rheingold, A. L.; Micalizio, G. C. J. Am. Chem. Soc. 2017, 139, 12374-12377.

(10) See Supporting Information for synthesis and characterization.

(11) Achmatowicz, O., Jr.; Bukowski, P.; Szechner, B.; Zwierzchowska, Z.; Zamojski, A. Tetrahedron 1971, 27, 1973-1996.

(12) Bowden, K.; Heilbron, I. M.; Jones, E. R. H.; Weedon, B. C. L. J. Chem. Soc. 1946, 39-45. 
(13) Desilylation of isomer 8 , followed by reprotection of the resulting hemiacetal, can provide a means for generating additional quantities of isomer 9.

(14) Itoh, T.; Jitsukawa, K.; Kaneda, K.; Teranishi, S. J. Am. Chem. Soc. 1979, 101, 159-169.

(15) Grieco, P. A.; Gilman, S.; Nishizawa, M. J. Org. Chem. 1976, 41, $1485-1486$.

(16) Ley, S. V.; Norman, J.; Griffith, W. P.; Marsden, S. P. Synthesis 1994, 1994, 639-666.

(17) (a) Gessler, S.; Randl, S.; Blechert, S. Tetrahedron Lett. 2000, 41, 9973-9976. For more on olefin metathesis, see: (b) Vanderwal, C. D.; Atwood, B. R. Aldrichimica Acta 2017, 50, 17-27. (c) Nicolaou, K. C.; Bulger, P. G.; Sarlah, D. Angew. Chem., Int. Ed. 2005, 44, 44904527. (d) Nugent, W. A.; Feldman, J.; Calabrese, J. C. J. Am. Chem. Soc. 1995, 117, 8992-8998. (e) Grubbs, R. H. Angew. Chem., Int. Ed. 2006, 45, 3760-3765.

(18) (a) Baldwin, J. E. J. Chem. Soc., Chem. Commun. 1976, 734736. (b) Ziegler, F. E.; Sobolov, S. B. J. Am. Chem. Soc. 1990, 112, 2749-2758. (c) Franzyk, H.; Frederiksen, S. M.; Jensen, S. R. J. Nat. Prod. 1997, 60, 1012-1016. (d) Bianco, A.; Celona, D.; Di Rita, S.; Guiso, M.; Melchioni, C.; Umani, F. Eur. J. Org. Chem. 2001, 2001, 4061-4066.

(19) Chang, S.; McNally, D.; Shary-Tehrany, S.; Hickey, M. J.; Boyd, R. H. J. Am. Chem. Soc. 1970, 92, 3109-3118.

(20) Nicolaou, K. C.; Prasad, C. V. C.; Somers, P. K.; Hwang, C.-K. J. Am. Chem. Soc. 1989, 111, 5330-5334. 